\title{
"Educación basada en Artes Liberales, una alternativa para una sociedad globalizada, indicios de su efectividad"
}

DOI: $10.46932 / \mathrm{sfjdv} 2 \mathrm{n} 2-110$

Received in: March 1st, 2021

Accepted in: May 30th, 2021

\author{
Maria Cristina Castrillon Toro \\ background PHD(c) \\ Current Institution Universidad San Francisco de Quito USFQ \\ Full address: Urb. prados de Tanda, C17S4 Cumbaya \\ E-mail.mcastrillon@usfq.edu.ec
}

\section{RESUMEN}

Actualmente, el conocimiento está en constante modificación y globalización por los avances que ofrece la tecnología, la necesidad de reforzar la formación general se basa en el reconocimiento de ciertas características de nuestros tiempos, que impactan directamente en nuestra forma de ver la educación universitaria. Más allá de la velocidad de la información están los evidentes cambios en la demanda de los mercados laborales, que requieren de un perfil nuevo de capacidades de los egresados universitarios, y a esto se suma que la formación debe ser relevante en un mundo donde existen problemas éticos, morales, económicos, sociales y políticos que nos llevan la necesidad de un pensamiento y reflexiones más críticas.

Esta investigación es relevante puesto que la Universidad San Francisco de Quito es la única en el país con esta filosofía y una de las pocas en América Latina, por lo que reflejar su eficacia puede ayudar a mejorar la oferta educativa y para la mejor toma de decisión de los egresados de colegios.

La investigación realizada esta basada en entrevistas cualitativas que buscan encontrar indicios de la efectividad de este modelo, analizando la trayectoria académica individual y revisando su vida laboral, de tal forma de ver con casos que muestren el beneficio de esta filosofía en educación.

El resultado obtenido fue muy halagador, el modelo permite que el estudiante se forme no solo en la carrera de su interés, sino que también pueda aprender lo que le gusta y amplía su mente, se ven buenos desempeños laborales, y logran desarrollar nuevas aptitudes laborales fácilmente, mejorando así su currículo.

Palabras clave: Artes Liberales, Sócrates - Método socrático, Trayectoria académica, Perfil del egresado, Éxito profesional, Realización de vida, Multi-disciplina.

\section{INTRODUCCION}

A través de la presente investigación se pretende analizar el impacto que la educación basada en la filosofía de las Artes Liberales de la Universidad San Francisco de Quito ha tenido en la vida de sus Egresado (egresados), en el ámbito profesional. La importancia de este análisis yace en poder conocer la influencia que esta filosofía llega a desempeñar en quienes fueron educados dentro de la misma, para de este modo tener indicios de su eficacia y de su relevancia dentro de la Universidad ecuatoriana San Francisco de Quito, que es la única en el país con esta metodología y una de las pocas en América Latina. 
La definición de Artes Liberales entra al mundo a partir de la Edad Media, donde culturalmente empezó un nivel de aceptación cada vez mayor. Para entender el término, debemos hablar necesariamente de trívium y quadrivium. La combinación que se obtiene con estas definiciones se determina por tri o quatri, en referencia a la cantidad tres y cuatro, y por las siglas vium que significan camino. Ambos términos enumeran tipos de ciencias que hacían parte de las llamadas Artes Liberales. Las primeras tres son la gramática, retórica y dialéctica, (Da Costa, pp. 143-145) mientras que las siguientes cuatro son la aritmética, astronomía, geometría y música (pp. 146-147). Ahora bien, el concepto de arte liberal fue heredado de la antigüedad clásica a partir de la idea de llevar a conseguir hombres en libertad, en contraposición a la idea de artes serviles, para de este modo cosechar conocimientos y destrezas de índole intelectual antes que hacerlo con labores especializadas o Artes Menores (trívium-quatrivium, 2009). En otras palabras, los estudios recibidos gracias a la filosofía de Artes Liberales contribuían al estudiante con una gama general pero cognoscitivamente abundante para su desarrollo dentro del ámbito ocupacional. La filosofía tratada en este planteamiento, que fue recopilada por el escritor Martianus Capella en sus escritos más importantes, pasó a tener más cabida en el Medioevo debido a su incorporación dentro de la Iglesia como enseñanza inherente para esta institución. Asimismo, una institución más se sumó a la adopción de esta enseñanza, y fue la universidad.

Para profundizar según el filósofo Sócrates, "la tarea de la dialéctica (y, por extensión, de la ciencia) es alcanzar los conceptos generales por medio de comparación entre hechos particulares (...) por llevar al sujeto al descubrimiento de la verdad, una verdad interna" (apuntesdefilosofía, 2009). Igualmente, cuando se cita a Bréhier en el escrito de Rocerau y Vilanova, donde se habla que "lo que con razón puede atribuirse a Sócrates son los razonamientos inductivos y las definiciones universales, situados unos y otras al principio de la ciencia” (p. 2), fuentes con las cuales se hace alusión directa o indirectamente a las Artes Liberales en su esencia y función. Además, otra idea básica para Sócrates que notamos, dice que el alumno no llega a recibir directamente el conocimiento inculcado vía el maestro, sino que el discípulo es quien extrae el conocimiento por sí solo a través de este diálogo, con lo cual podemos afirmar que el método socrático sí anuncia la ayuda del profesor como parte del camino hacia el saber, más no como el generador directo del mismo; es decir, se basa en potenciar esa falta de impulso del estudiante hacia el conocimiento.

Es importante resaltar el hecho de que con el transcurso del tiempo el concepto de artes liberales de la Edad Media fue tomando otros nombres, sin necesidad de cambiar su significado, entonces pasó a ser parte del término humanismo ya en la época renacentista.

A la vez, es evidente que el término humanismo es asociado a un gran periodo de agitación cultural en Europa, se hace referencia, por supuesto, al Renacimiento, época de revolución en las estructuras de pensamiento y de vida social, política, económica y artística, que pasaba la energía 
de la comprensión del mundo a las fuerzas humanas (Aldana, 2009, p. 12).

Durante este momento histórico, las artes liberales se verían ilustradas a través del humanismo renacentista, derivado de Cicerón y Quintiliano y donde se seguía hablando del los estudios libres del hombre libre (p.12). El humanismo permite según Aldana "que las personas reconozcan su necesidad de alimentar y nutrir su interioridad, sus cualidades personales (...)" (2009, p. 19). Esto es lo que caracteriza a las artes liberales, pues el humanismo busca integrar al individuo como tal para su desarrollo personal y profesional, ya que le permite abrirse campo a otras virtudes y aptitudes, a la vez que permite la reflexión del mismo y del entorno que lo rodea. Esto permite formar individuos más reflexivos e íntegros con su sociedad, pues dentro de la educación en artes liberales se incluye las ciencias sociales, ciencias humanas y las ciencias naturales o experimentales (Aldana, 2009, p. 13). Esta educación holística permite al ser humano abrirse campo dentro ya sea de su especialidad o de su entorno social tanto para resolver problemas o involucrarse de forma integral en situaciones que requieren un análisis crítico del mismo, pues con las artes liberales, el ser humano está preparado para desenvolverse en cualquier ámbito, con una mirada humanista que favorece la integración del ser con el entorno, sin excluir patrones que son parte del desarrollo cultural del individuo dentro de la sociedad. Más relevante incluso es cuando se sugiere la potencia del término universitas (unión en la diversidad) forjada dentro del mismo hombre (Aldana, 2009,) y la manera en que este humanismo "se enfrenta radicalmente a todo tipo de alienación, en la medida que busca engrandecer la reflexión sobre lo humano y la acción humana misma, perfeccionando a la persona" (p.14), donde se señala el proceso inverso de la alienación que es igual al humanismo: "busca unidad, incorporación, integralidad, ensanchamiento" (p. 14), lo cual genera en el estudiante una diferenciación y abundancia únicas que vienen del surgimiento intelectual generado sobre sí mismo, y no a partir de una metodología algo dictatorial, sino más bien libre. La misma formará nexos entre la diversidad de conocimientos y dará como resultado un egresado con una serie de características más privilegiadas.

La trayectoria académica de los alumnos de la Universidad San Francisco de Quito posee, sin duda, a las Artes Liberales y al método socrático como parte de este proceso de desarrollo del conocimiento. Para definir esta terminología, podemos recurrir a la cita de Altamira Rodríguez en la divulgación de Zandomeni y Canale, donde trayectoria académica se determina como:

La cuantificación del comportamiento escolar de un conjunto de estudiantes (cohorte) durante su trayecto o estancia educativa o establecimiento escolar, desde el ingreso, permanencia y egreso, hasta la conclusión de los créditos y requisitos académico-administrativos que define el plan de estudios (p. 61).

Las expresiones de estos itinerarios llegan a ser muy sistemáticos y evaluables, pues estos "son indicadores de uso habitual para la caracterización de los tipos de recorridos escolares de los alumnos, sin 
dejar de reconocer una clara asociación de los mismos con los desarrollos teóricos-metodológicos (...)" (p. 62). No obstante, la idea de involucrar a este término dentro de este documento tiene la intención de mirar críticamente cómo esta trayectoria puede verse afectada o transformada por estar directamente relacionada a la filosofía de las Artes Liberales, lo cual, y también para este análisis, conlleva el “identificar grupos de alumnos que han seguido similares itinerarios y, a partir de allí poder avanzar en el reconocimiento de los posibles factores que han influido en los distintos recorridos" (p. 64), y evaluar si esta influencia ha sido negativa o positiva.

De la misma forma debemos determinar las competencias con las que salen los alumnos de la universidad y así determinar cuál es su perfil para determinar si hay un concepto único o existe una generalidad donde nos podamos asentar para el estudio , según Romero:

Para identificar la competencia y diseñar el perfil del egresado se parte de considerar las demandas, requerimientos y necesidades específicas del área que se atenderá. Se parte de la creación de un perfil de egresado, que nace de la indagación en literatura y el campo laboral para ir generando así las competencias mismas que deberán ser sometidas a un proceso de validación. (p.12, 2005).

Es así como se genera un modelo de educación basado en metodologías aprobadas y designadas para dicho modelo educativo, debido que todo se ajusta a la demanda de la educación y de la sociedad. Por lo que según Romero la creación de las competencias en el perfil de egresado son los siguientes: Calidad en el proceso de formación del egresado, eficiencia y flexibilidad en el modelo para la adquisición de las competencias, flexibilidad en el proceso de formación general, optimización de recursos de procesos de enseñanza aprendizaje, integración de los actores del proceso de enseñanza aprendizaje que se basa en unos currículos integrales donde se fundamenta en una constante interacción comunicativa. (p. 12, 2005). Aquí se resalta la flexibilidad en el modelo, puesto que no es de derecho absoluto de la universidad el establecer que deben estudiar sino que flexibiliza el modelo para poder brindar un abanico de oportunidades que permitan enriquecer el conocimiento a cargo de los alumnos o sugerido por la institución.

Para poder cubrir con el objetivo de medir el éxito profesional se determina que estas se miden en competencias, de esta manera se podrá garantizar un desarrollo optimó en el ámbito profesional. Según Viviana y Rosa González:

El desempeño profesional eficiente en una sociedad globalizada y del conocimiento exige, además de las competencias específicas propias del ejercicio de una determinada profesión, competencias genéricas o transversales, que se expresan en diferentes profesiones, tales como: la capacidad de gestionar de forma autónoma y permanente el conocimiento, de investigar, de trabajar en equipos, de comunicarse en un segundo idioma y de aprender a lo largo de la vida. (p. 191, 2008). 
Esto quiere decir que una educación holística que permita al estudiante abrir su campo de estudio sin limitarlo a enfocarse en un solo ámbito permite que el estudiante se forme con criterio más analítico, que le permita resolver problemas y poder desenvolverse en cualquier ámbito, gracias a que podrá tener buenos criterios de manejo de grupos y resolución de conflictos. Además de que una educación basada en competencias motiva al estudiante a abrir su zona de confort y le permite experimentar y desarrollarse en otros ámbitos, como se menciona anteriormente, desarrollar otras habilidades como aprender otro idioma amplían las áreas de desarrollo del estudiante, volviéndolo más competitivo y apto para ejercer profesión en diversos ámbitos laborales.

De esta manera, las trayectorias académicas y las competencias adquiridas favorecen el éxito profesional del estudiante y futuro profesional, pues la persona no tendrá límites en ejercer profesión y lo mejor de todo es que gracias a las competencias adquiridas podrá emprender, y no solo enfocarse en un sólo ámbito, lo que lo vuelve un ente generador de economía estable para la sociedad, y sobre todo, ofrecerá estabilidad para él/ella mismo; y es que "La capacidad creativa, la capacidad crítica y autocrítica y la capacidad para tomar decisiones ocupan lugares prioritarios (González y González, p. 201,2008). Esto caracteriza a un estudiante con probabilidades de éxito profesional, pues mientras más habilidades él/ella tengan, más posibilidades de alcanzar el éxito tendrán, y sobretodo, destacarse de los demás.

Si entramos en el tema de destacarse de los demás debemos mencionar aún más características, como la educación multidisciplinaria, que retomando el tema de Trivium que agrupaban disciplinas literarias como la gramática, la retorica y la dialéctica asi como Quadivium, estos agrupaban disciplinas científicas que se relacionaban con las matemáticas como la aritmética, geometría, la muscia y la astronomía, pensando en este principio básico de las Artes Liberales, esta prepara al estudiante a competir consigo mismo por aprender y alcanzar metas nuevas, y es que al no limitar el conocimiento, abre las posibilidades de nuevas formas de aprendizaje, "es una composición no-integradora de varias disciplinas, en las que cada una conserva sus métodos y suposiciones sin cambio o desarrollo de otras disciplinas" (Rodríguez, 2014). Lo interesante de las multi-disciplinas es ver que aún se conserva, como lo dice Rodríguez, los métodos de las demás, por lo tanto se tienen algunas formas de procesar la información o desarrollar. Por otro lado, también es importante notar que no va a existir un desarrollo amplio de cada una ya que no se llega especializar en ninguna. Conocer de diferentes ramas y concentrarse en algunas puede llevar aun entendimiento más amplio de los diferentes temas que se pueden llegar a tratar. Se respetan las diferentes disciplinas entre ellas y contamos con el apoyo de diferentes capacidades unidas en un solo resultado.

Es así como las multi-disciplinas desarrolladas por los estudiantes, garantizan una mejor educación y formación para ser profesionales mejor capacitados para enfrentarse al mundo laboral tan competitivo 
de hoy en día. Este desarrollo integral permite al futuro profesional sentirse seguro y apto para enfrentar al mundo laboral ya sea con emprendimientos o innovación para su área de preparación, y así alcanzar su realización de vida. Y es que según Ardila, la calidad de vida es cuando "se empieza a trabajar en el crecimiento personal, las realizaciones de las potencialidades, el bienestar subjetivo y otros temas similares". (p.162, 2003). Y es que el hecho de que su formación se base en multi-disciplinas y libertad permite que la persona se sienta segura y por ende tenga satisfacción general cuando se gradúe, pues según Ardila "es satisfacción general, que surge de realizar las potencialidades que el individuo posee. Realización personal y calidad de vida son dos aspectos que se han ligado, y que sin duda están altamente correlacionados" (p.163, 2003). Es así como tener una educación amplia permite expandir los horizontes y metas de vida del estudiante, además de motivarlo a seguir mejorado como profesional lo que hace que la persona sienta que deba competir consigo mismo lo cual lo vuelve una persona capaz de superar a los demás y así mismo. Es así como el éxito profesional, la educación con multi-disciplinas y la realización de vida en conjunto influyen para una formación íntegra que genere profesionales y seres humanos aptos para enfrentar las realidades que la sociedad impone con seguridad y soluciones que permitan que la sociedad progrese para bien común.

"Las artes liberales que proveen a un ser humano de la visión del mundo, de poder entender el planeta y entenderse a sí mismo, sin la dinámica de la universalización generalizada de los procesos, sino que cada uno sea lo que quiere ser" German Maldonado en su conferencia Ted X Usfq, es muy claro con el propósito final de un proceso educativo basado en Artes liberales, la pregunta de investigación es si finalmente y después del proceso educativo hay evidencias que demuestren el éxito del mismo en sus egresados, a continuación la descripción de la metodología y la investigación.

\section{METODOLOGIA}

Dentro de los últimos datos estadísticos en el senescyt (Secretaria Nacional de educación superior) se pudo notar un incremento del $16.85 \%$ del registro de títulos universitarios, lo que me llevó a pensar en una tendencia creciente estos años, esta tendencia se va a ver contrarrestada con el índice de empleo o subempleo para un análisis más objetivo 
SNIESE; tal como lo determina el artículo 19 del reglamento a la Ley Orgánica de Educación Superior. El valor mencionado, representa un incremento del 16,85\% con respecto al 2014.

Gráfico No. 15. Certificado de registro de títulos

1.803

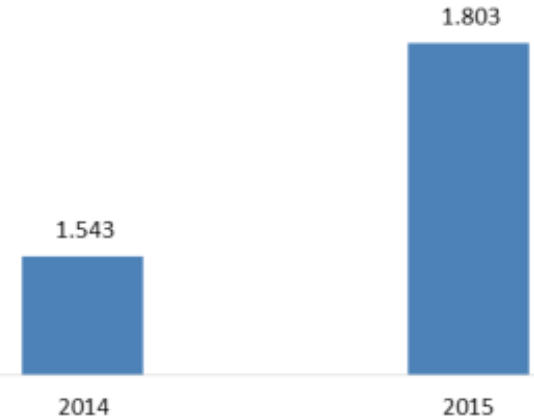

Fuente: Subsecretaría de Formación Académica y Profesional

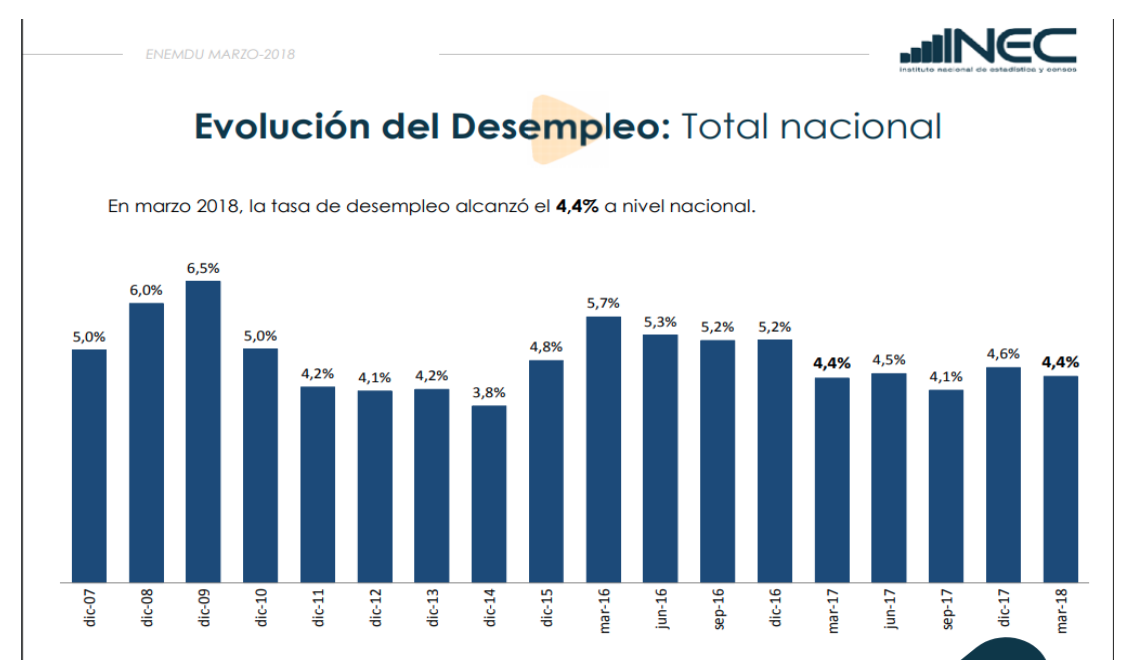

Dentro de las estadísticas del desempleo en el Ecuador publicadas por el Inec (Instituto de estadísticas y censos) se observó que en los años 2015, 2016 hubo un alza en el desempleo hasta marzo del 2017 cuando bajó manteniéndose en el mismo rango entre 4,4 a 4,1. Por lo que el desempleo está con una tendencia a mantenerse. El mercado ecuatoriano está muy sobrepoblado de profesionales como se refleja en el siguiente gráfico en donde se muestra la el aumento de subempleo y trabajo no pleno.

En el Ecuador hay distintos factores que influyen a la hora de conseguir trabajo por lo que tener diferentes cualidades y destrezas multidisciplinarias aporta un plus a los profesionales que a la hora de conseguir trabajo encuentran una gran competencia. 


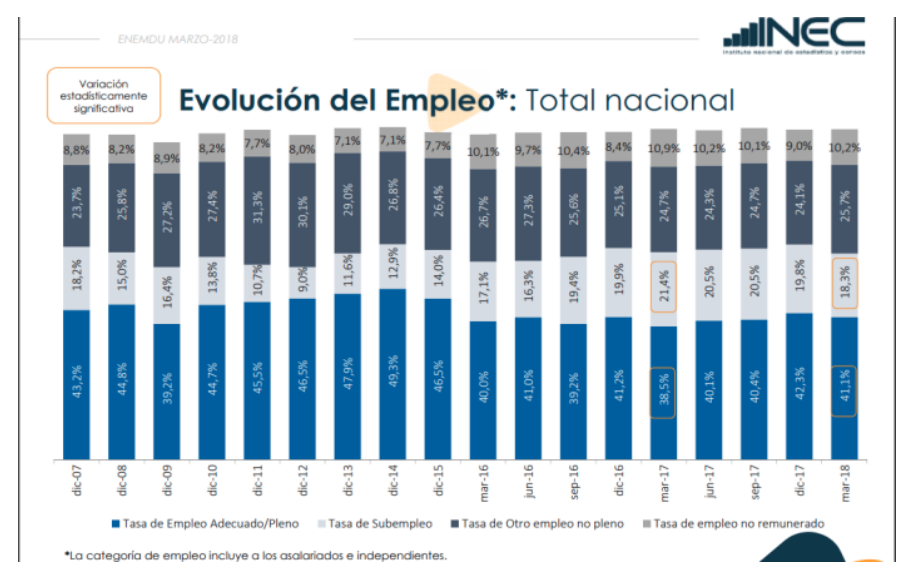

\section{METODOLOGIA CUANTITATIVA}

\subsection{ENCUESTAS}

Se escogió una Investigación descriptiva, "La investigación descriptiva busca especificar propiedades, características y rasgos importantes de cualquier fenómeno que se analice" (Martinez, Ramirez y Flores, 2003, pp. 119)

Sobre la base de un universo de 8500 alumnos fluctuantes en la USFQ. El tamaño de la muestra es determinado estadísticamente con la fórmula de Muestreo Aleatorio Simple teniendo en cuenta un nivel de confianza del $90 \%$ con un margen de error de $10 \%$ obtuvimos que el tamaño de la muestra debe ser de 67 personas.

\section{a. Análisis de la muestra}

El tamaño de la nuestra muestra fue de 67 personas, las cuales están divididas entre estudiantes de los distintos colegios, graduados (Egresado) y profesores desglosados en cantidades a continuación:

\begin{tabular}{|l|l|}
\hline Profesión & Número de encuestas \\
\hline Estudiantes & 30 \\
\hline Profesores & 7 \\
\hline Egresado & 30 \\
\hline
\end{tabular}




\section{b. Resultados}

Sexo
50 respuestas

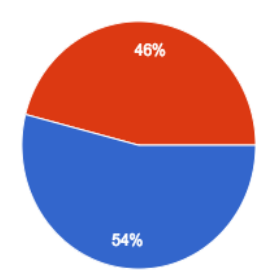

Edad

M

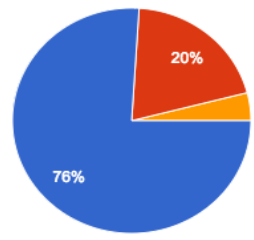

1. ¿Qué carrera estudias/estudiaste en la USFQ?

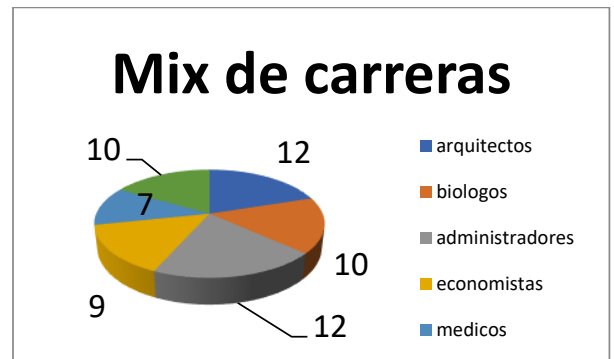

En respuesta a esta pregunta encontramos una variedad muy interesante de personas entre ellos arquitectos, biólogos, ingenieros, comunicadores, médicos, etc. También importante revisar el mix de alumnos actuales y egresados es 36\%-64\%, con el fin de ver los pesos en sus respuestas.

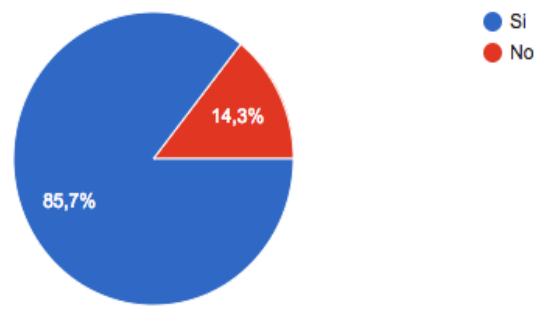


Nos damos cuenta que la información impartida entre los estudiantes de la universidad San Francisco de Quito llega correctamente con el 85,7\% diciendo que sí. La gran parte de la muestra indica tener idea de cómo funciona las artes liberales como metodología de educación
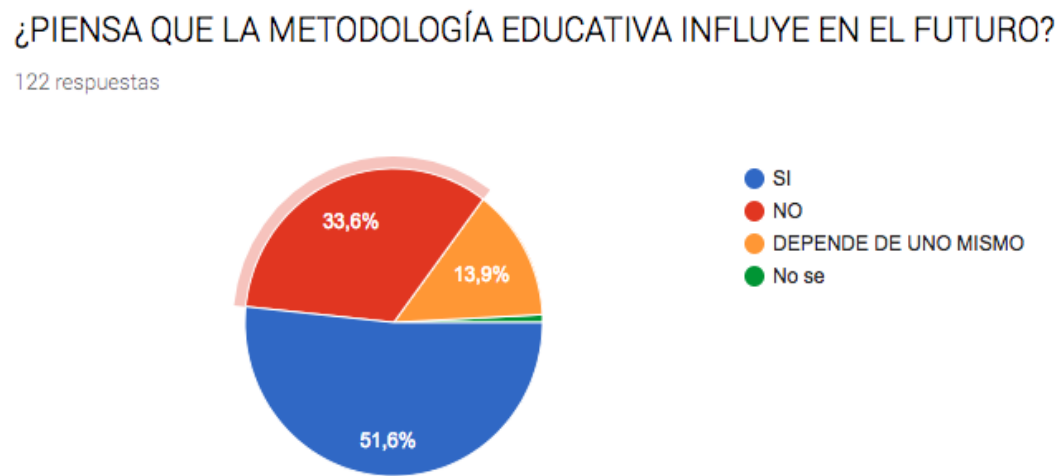

$\mathrm{SI}$

NO

DEPENDE DE UNO MISMO

No se

Dentro de la muestra que la mayoría contestó Sí siendo el 51,6\% y otro grupo segmentado siendo el $33,6 \%$ y un $13,9 \%$ contestando que depende de uno mismo. Vemos que la información está sesgada y dentro de muestra hay diferentes opiniones frente a este tema.

\section{CREES QUE TU FORMACIÓN PROFESIONAL INFLUYE EN TU VISIÓN DEL} MUNDO
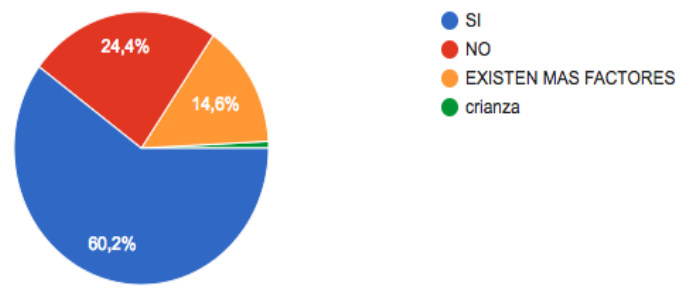

EXISTEN

El $60 \%$ por de muestra coincidió que sí influye mucho en tu personalidad la carrera que sigues. Las diferentes respuestas están sesgadas pero la mayoría piensa lo mismo. Solo el 24,4\% respondió que No siendo un porcentaje bajo. 


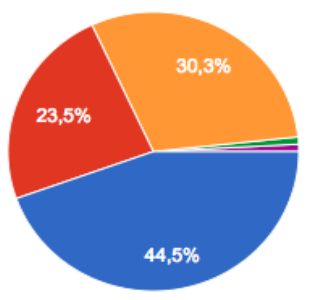

ARTES LIBERALES

Modelo de la pedagogia tecnicista o

conductista.

TRADICIONAL

- Sistema Finlandés

No se

Un 44,5\% coincide que las artes liberales es un buen modelo educativo. El 30\% piensa que la educación tradición es un buen modelo siendo el segundo más escogido. Los diferentes modelos de pedagogía tecnicista o conductista es el tercero más escogido por metodología de implementar una conducta dentro de la persona de manera espontánea más no de memoria.
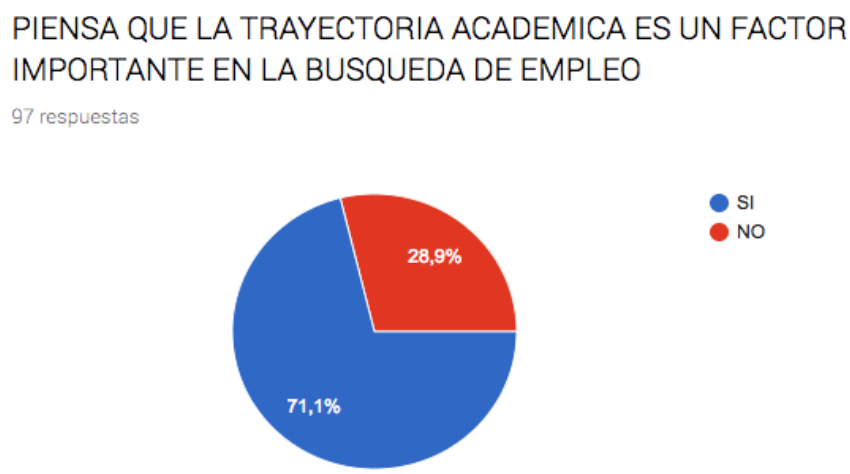

Los diferentes conocimientos adquiridos proveen de mayor información y mejor capacidad de respuesta en las entrevistas para la búsqueda de empleo. ¿CREE QUE LA FACILIDAD DE TOMAR MATERIAS ELECTIVAS AYUDA EN
ALGO SU RENDIMIENTO LABORAL

120 respuestas

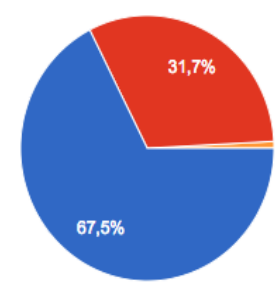

SI

Depende de las materias electivas 
La toma de materias electivas ha facilitado la especialización de los egresados de la universidad San Francisco de Quito. La multidisciplinariedad aplicada en el modelo de las artes liberales facilita en la mejora de sus habilidades laborales dentro de su profesión. Un pensamiento más abierto y tolerante ayuda a los egresados a estar a la par con la contemporaneidad de la actualidad.

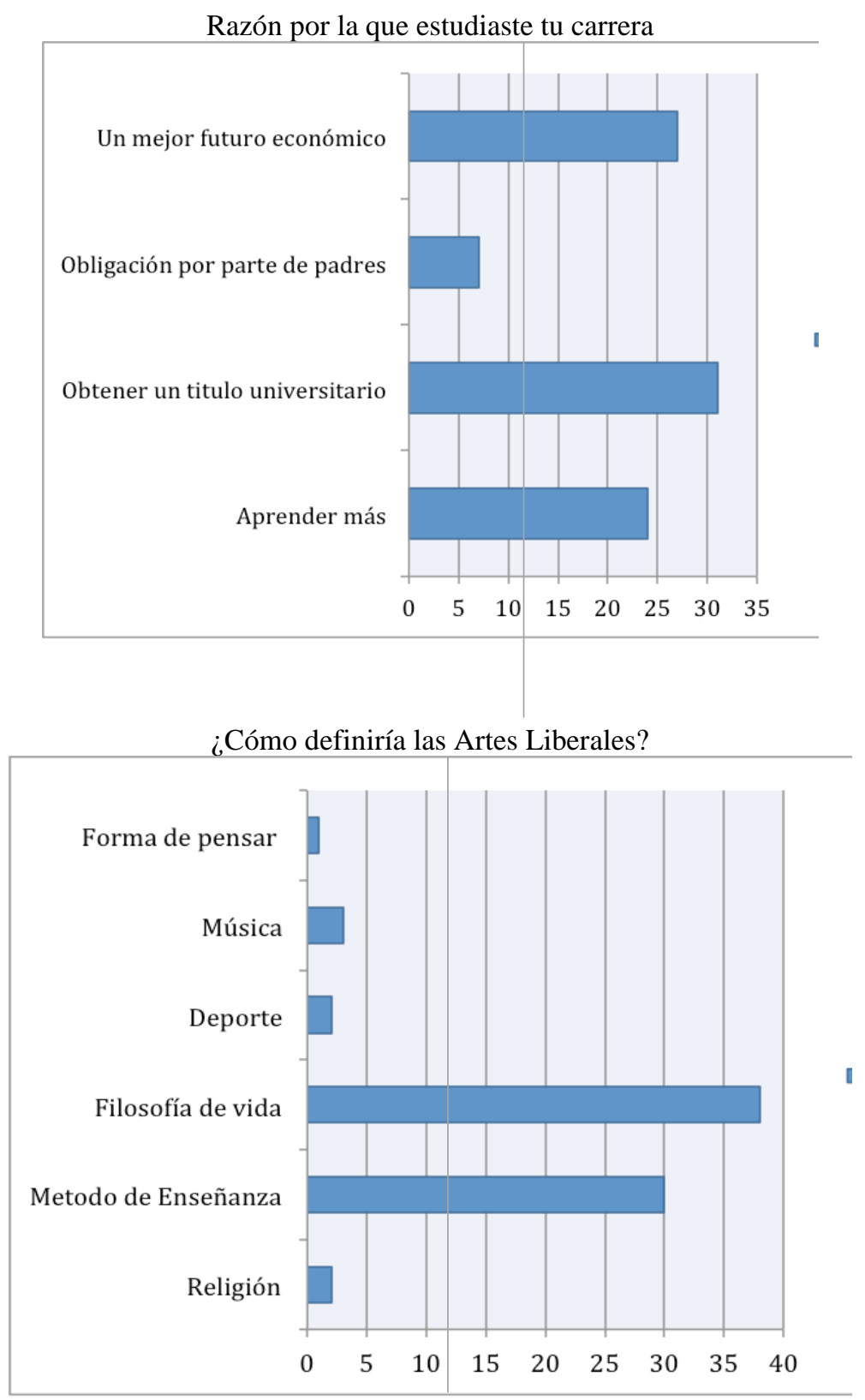



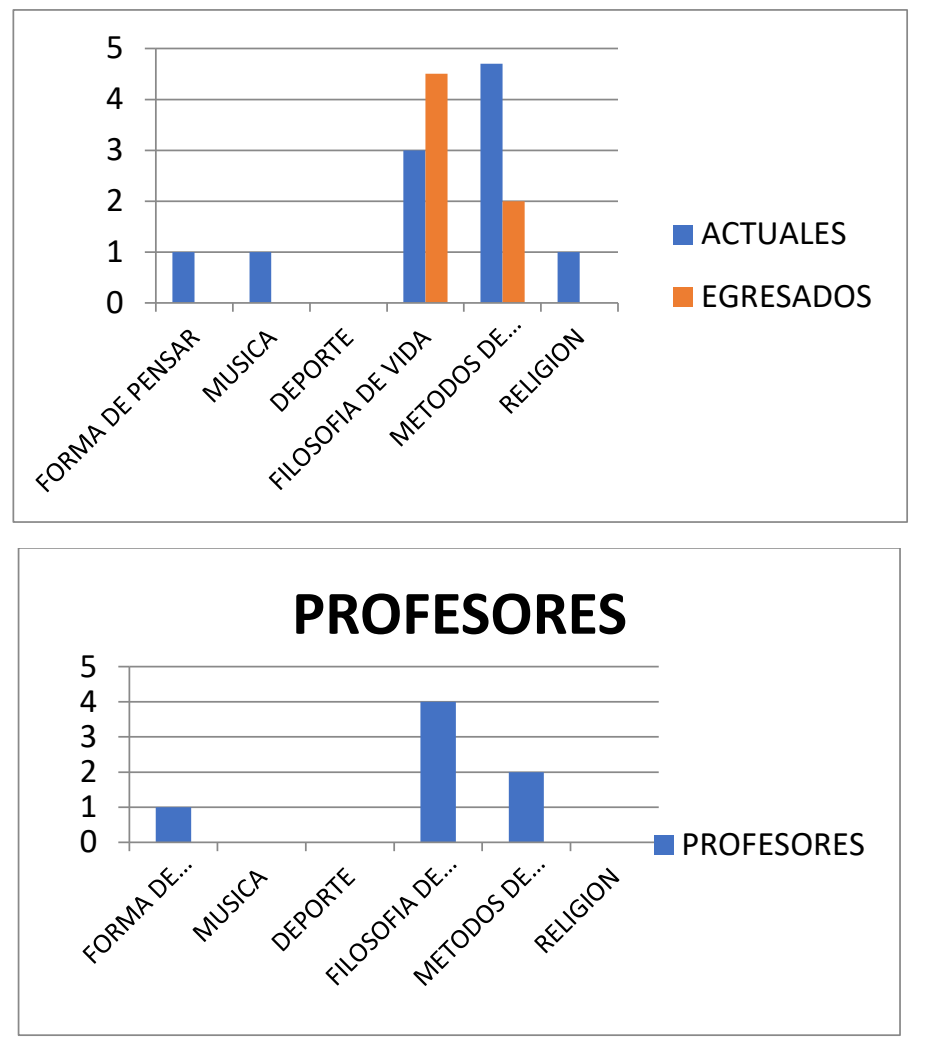

Abriendo esta pregunta para conocer la forma de ver de un alumno actual de la universidad y de un egresado, se puede ver el peso que dan a la filosofía de vida vs el método de enseñanza, los alumnos egresados o egresado, entienden al finalizar sus estudios que fueron impactados no por un método de enseñanza sino que les ayuda para su vida diaria.

4. ¿Las Artes Liberales te han ayudado en tus estudios, tu vida profesional y tu parte social?

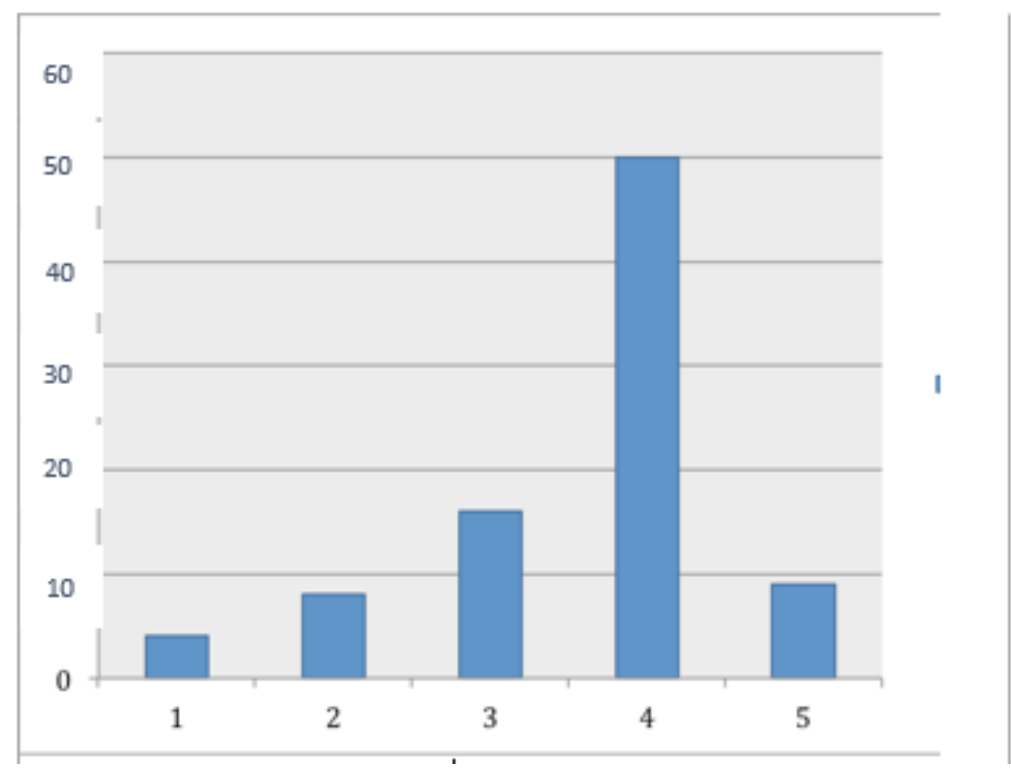

Siendo 1 poco y 5 mucho. 


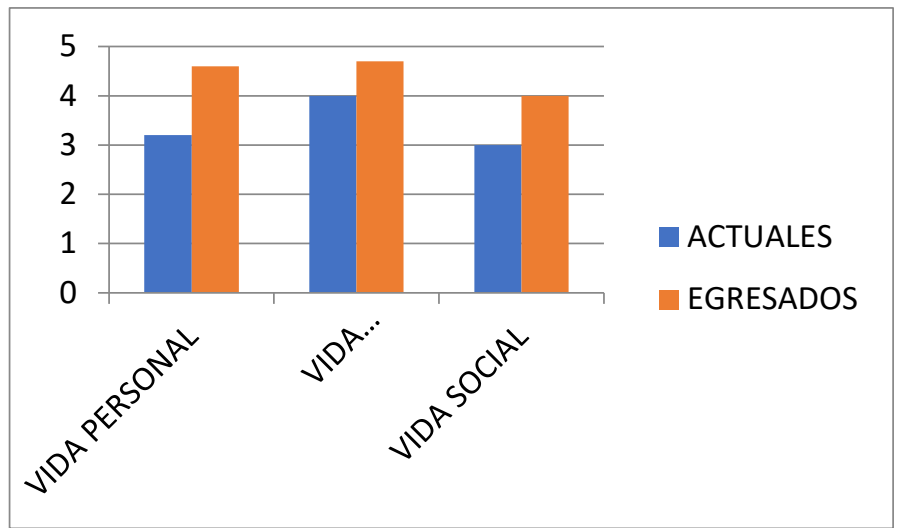

5. ¿Has aplicado las artes liberales en la vida cotidiana?

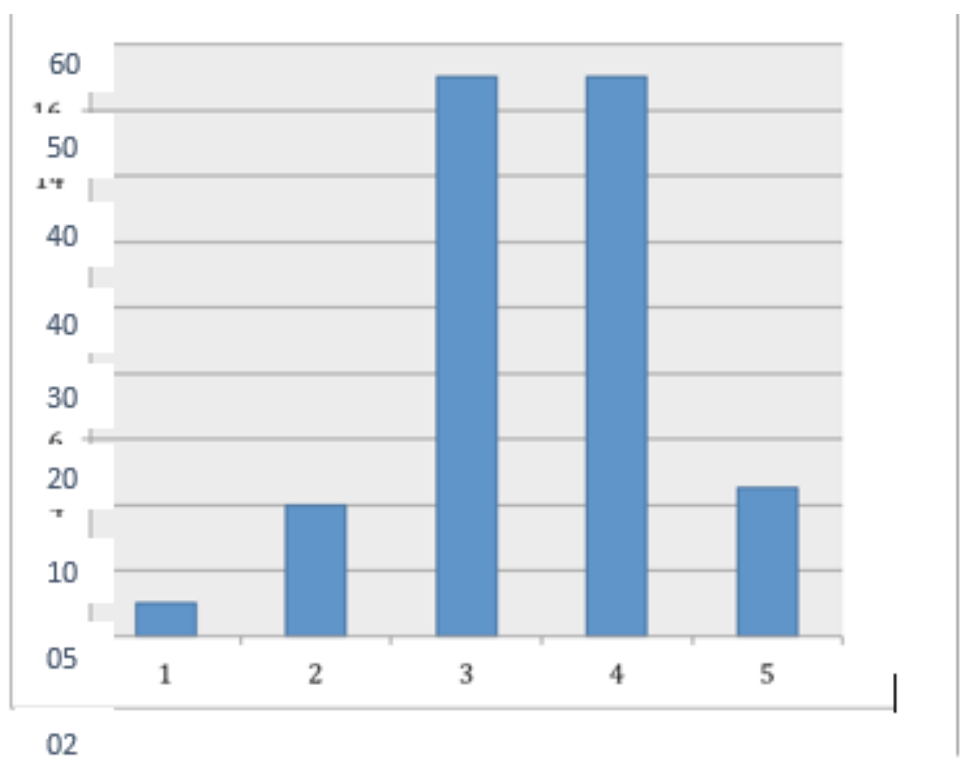

Siendo 1 poco y 5 mucho.

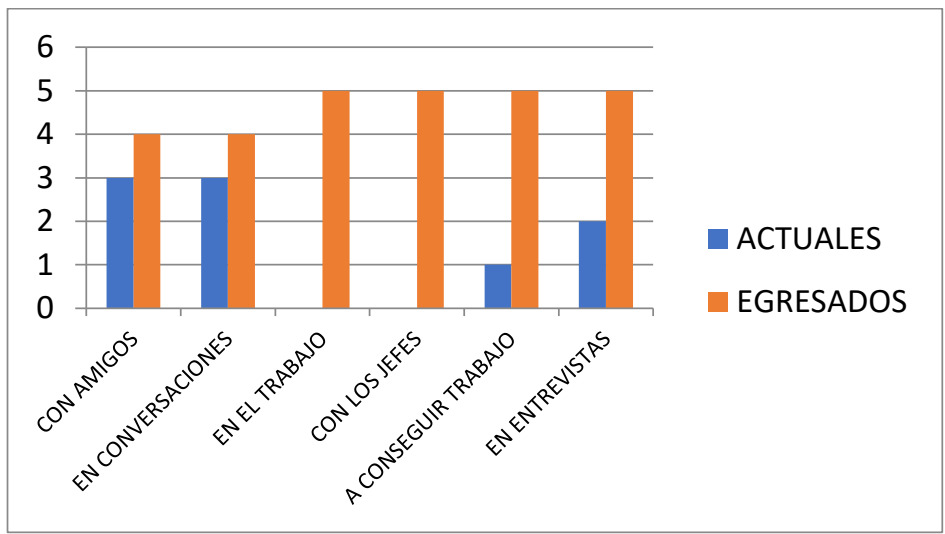




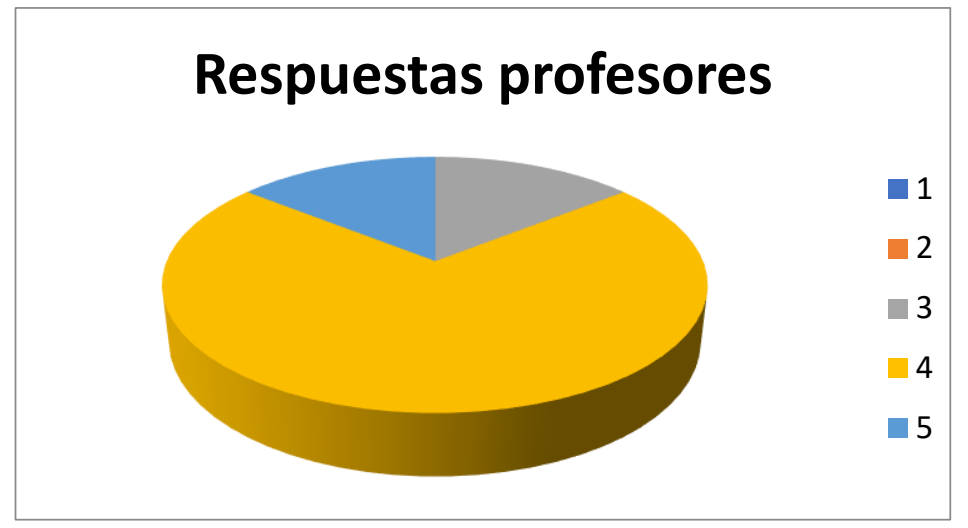

\section{Respuestas profesores}

Siendo 1 poco y 5 mucho

Los profesores por su lado tienen una visión más clara sobre artes liberales, la mayoría ven la utilidad de esta y no tienen reparos en mencionarlo

6. ¿Crees que las Artes Liberales marcan una diferencia en el estudio universitario con respecto a otras universidades?

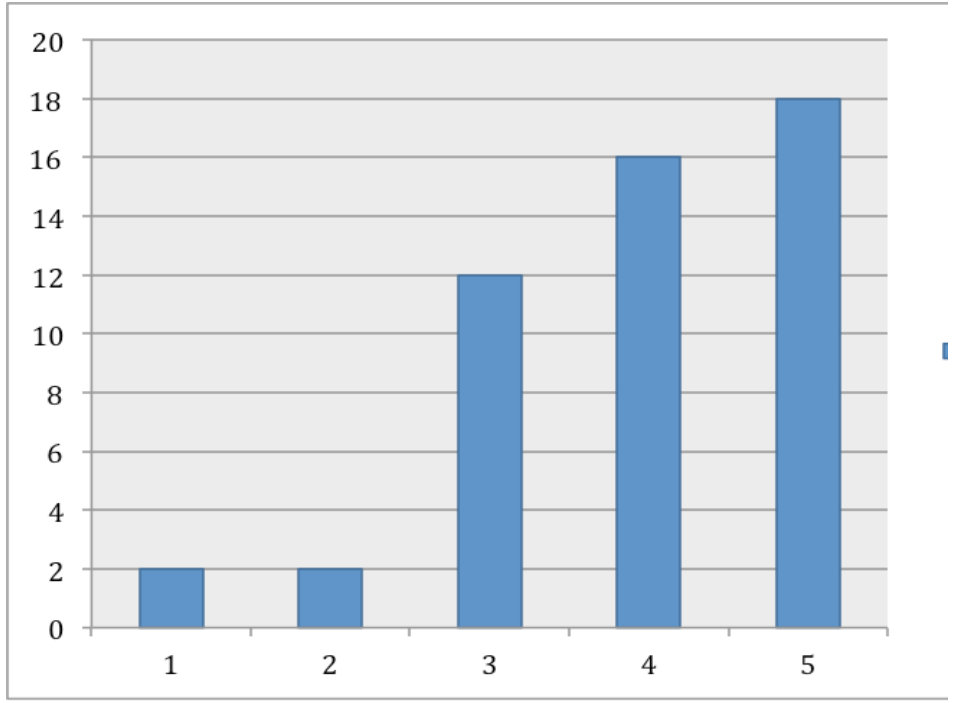

Siendo 1 poco y 5 mucho.

\section{Respuestas profesores}

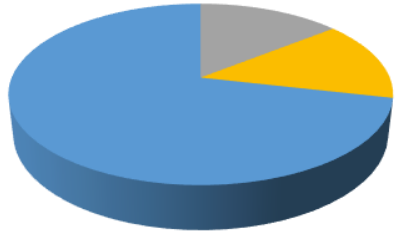


En las entrevistas a profundidad puede verse con mayor claridad su posición pero es nuevamente claro que el personal docente, ve una diferencia muy grande comparada con otras universidades, aquí es importante mencionar que no se habló de una en particular ni si es pública o privada, simplemente se abrió la pregunta en general y la respuesta es bastante general también.

7. ¿Las Artes Liberales cambiaron tu perspectiva de vida?

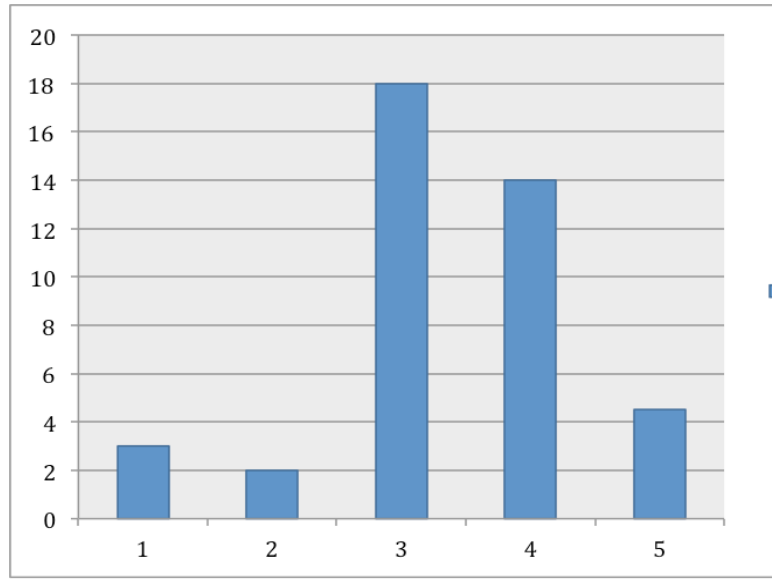

Siendo 1 poco y 5 mucho
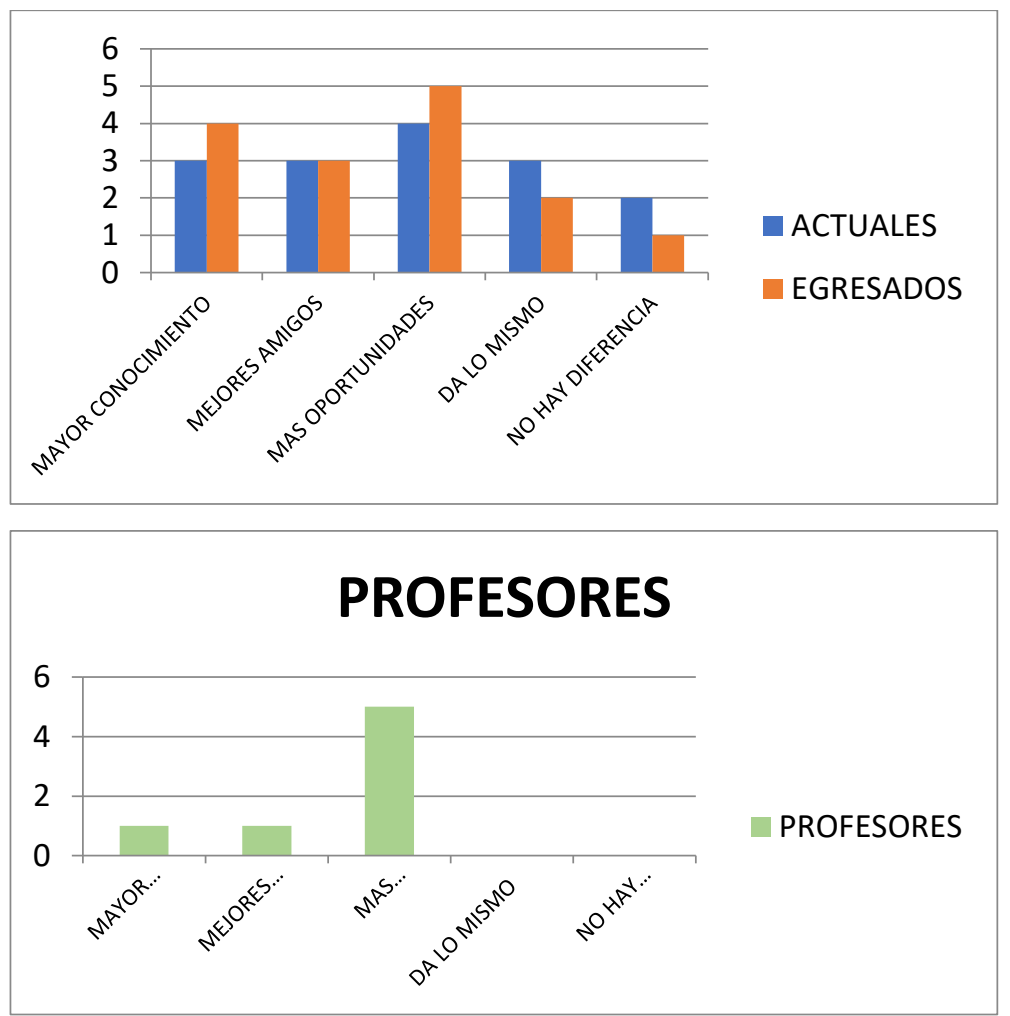
Las respuestas aquí son relevantes cuando se cruzan con las entrevistas, se ve que disfrutan la universidad y la ven como una oportunidad para ellos y para los alumnos. También mencionan que es una oportunidad grande ser parte de esta comunidad universitaria.

8. ¿Cuándo piensas en Artes Liberales cuales son las 3 primeras palabras en las que piensas? Al ser esta una pregunta abierta y no obligatoria, se buscó saber de una manera más empírica, que piensan las personas sobre las artes liberales y si es que estas llegaron a influenciar en la personalidad de cada uno de los encuestados. Entre las palabras más comunes encontramos:

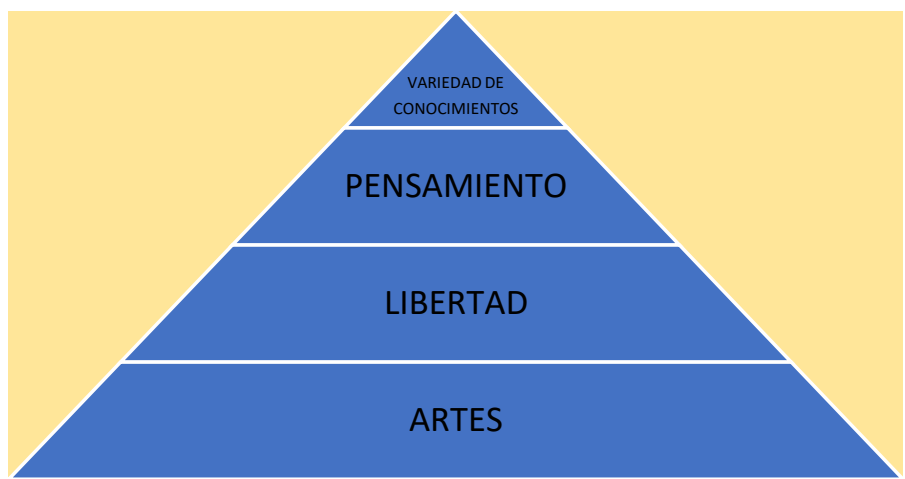

\section{INVESTIGACION CUALITATIVA}

\subsection{ENTREVISTAS A PROFUNDIDAD}

Para la ejecución de las entrevistas se decidió realizar en un solo colegio académico, en este caso de la carrera de Comunicación Publicitaria, se hicieron 5 entrevistas a egresados y también se conversó con 2 a profesores tiempo completo que tienen más de 20 años de experiencia y constituyen pilares importantes dentro de la comunidad académica.

De las clases optativas, colegio general socráticos, etc. que tiene la universidad, ¿sientes que alguna contribuyó de manera considerable en tu actual carrera profesional? Describir el nivel de contribución. 


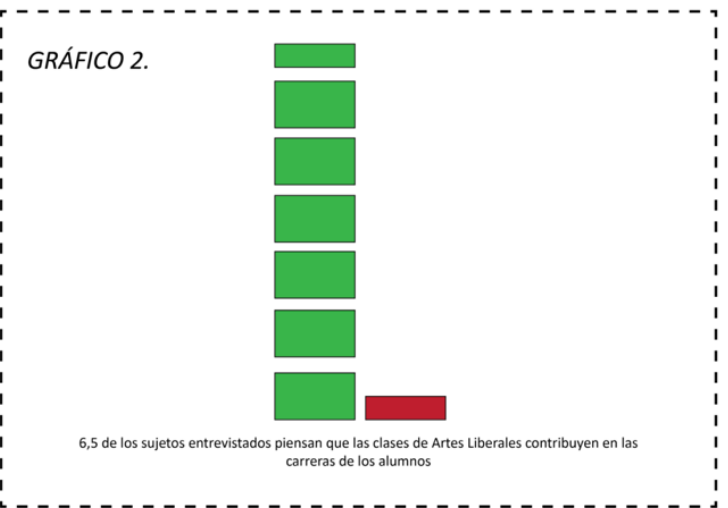

En esta segunda interrogante, solamente un Egresado dice no haber sentido que las clases de Artes Liberales contribuyeron en su carrera de Comunicación Publicitaria. Por otro lado, tanto egresados como docentes afirman que dichas clases sí contribuyen de gran manera principalmente porque "todos los conocimientos están relacionados" (Rodríguez, 2018), y es muy repetitivo el comentario de que no solo les sirvieron para su vida profesional, sino asimismo en su vida personal. Como menciona Aldana, este tipo de aprendizaje contribuye de manera holística, que las personas reconozcan su necesidad de alimentar y nutrir su interioridad, así el ser humano se abre campo dentro ya sea de su especialidad o de su entorno social, para resolver problemas e involucrarse de forma integral (2009, p. 13).

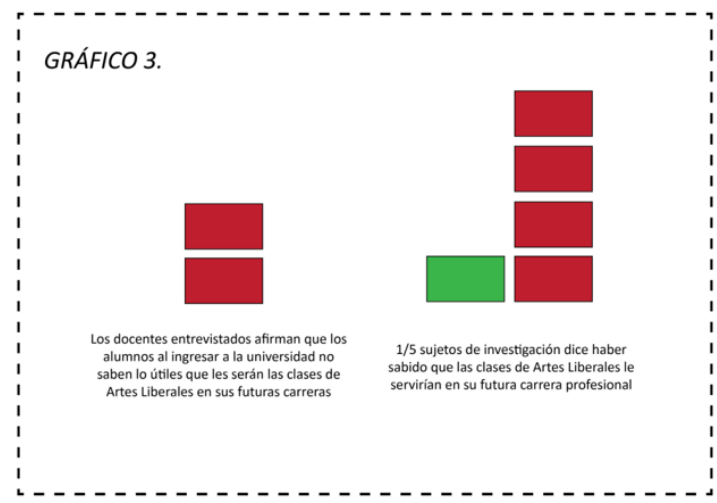

Ya en la pregunta 3, un problema en cuanto a las Artes Liberales fue notado. La pregunta aludía a saber si los alumnos al ingresar a la universidad tenían la certeza de que las clases de Artes Liberales serían útiles en sus futuras vidas profesionales, ante lo cual tanto el $100 \%$ de los profesores de estas entrevistas como el 80\% de los Egresados con los que hablamos dicen que esta noción de beneficio sobre dichas clases no es recibida; no obstante, Ruth Rodríguez, profesora a tiempo completo de COCISOH, asevera que es responsabilidad de los profesores cumplir con la comunicación de este factor y siempre relacionar los distintos conocimientos dentro del aula (2018). Como lo dice Zabalza (2013), habla de lo fundamental que es la docencia dentro del proceso del estudiante en una educación socrática, lo cual 
fortalece el argumento de Rodríguez, para poder convertir en realidad el potencial del aprendizaje del estudiante (p. 64).

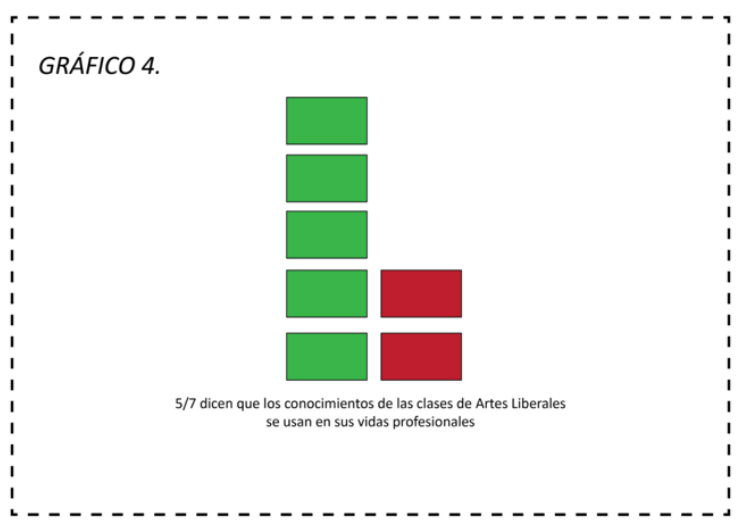

Al preguntar a Egresados publicistas de la USFQ y a profesores si los conocimientos aprendidos de las clases de Artes Liberales han sido usados en las vidas profesionales de los graduados, el $40 \%$ de los Egresados nos dice que piensan no haberlos utilizado hasta el momento, por otro lado el $60 \%$ restante de sus similares y ambos docentes dicen que estos conocimientos sí se usan en la profesión publicitaria. Muchos nos comentaron que dentro de esta carrera es primordial conocer de todo un poco, ya que los clientes son diversos y un día puedes comunicar para una marca de chocolates y el siguiente día realizar una campaña electoral. Aquí las Artes Liberales cumplen un papel fundamental al generar un amplio espacio de conocimiento y además volver versátiles a quienes fueron parte de su educación.

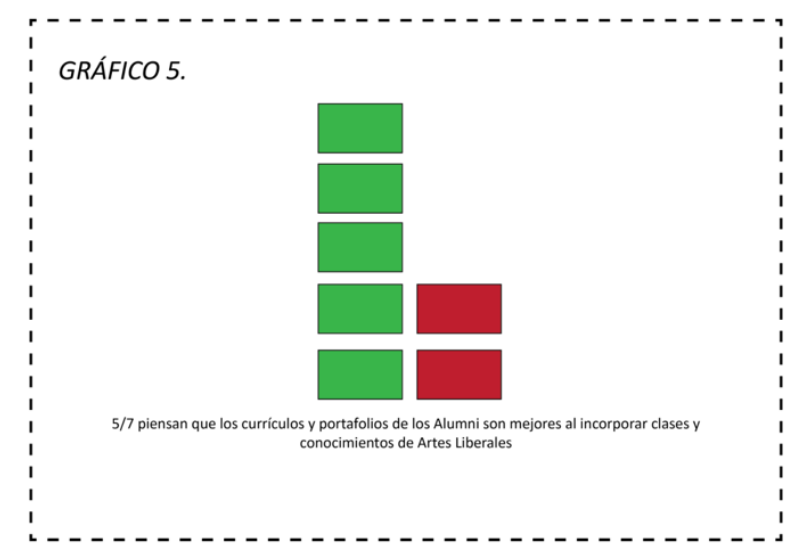

Al preguntar: ¿Sientes que tu currículo y portafolio son mejores al haber incorporado dichas clases dentro de los mismos? y preguntar lo mismo a los profesores de la universidad, dos Egresados nos respondieron no creer que sus portafolios y cvs son mejores al incorporar clases de Artes Liberales en los mismos. Otro dato interesante aquí fue que esta respuesta depende del mercado al que se aplica, en este caso, las agencias de publicidad del país, donde depende que tanto valor le den ellos como empresas a este tipo de factores dentro de un perfil de egresado. 


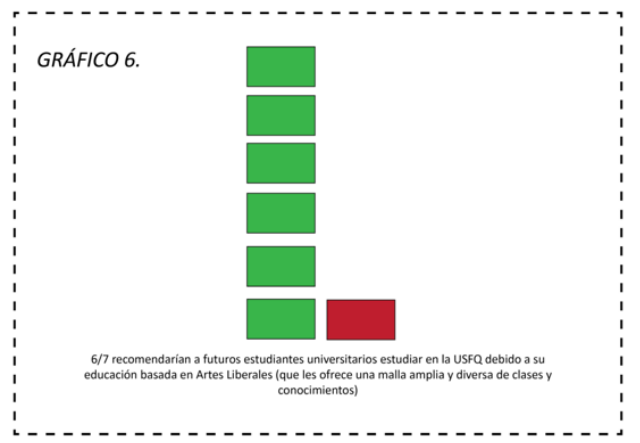

Al realizar una nueva pregunta para saber si recomendarían a futuros alumnos de universidad ingresar a la Universidad San Francisco de Quito debido a esta educación basada en Artes Liberales, 6 de los 7 entrevistados nos afirmaron que sí lo harían. Además, Rodríguez (2018) plantea que este tipo de educación debería ser pensada y aplicada para todas las instituciones del país. Una Egresado, María Elena Páez, nos comenta que recomendaría a la USFQ por esta razón, ya que no solo hay variedad de clases, sino que también uno como estudiante tiene la libertad de escoger a su gusto (2018).

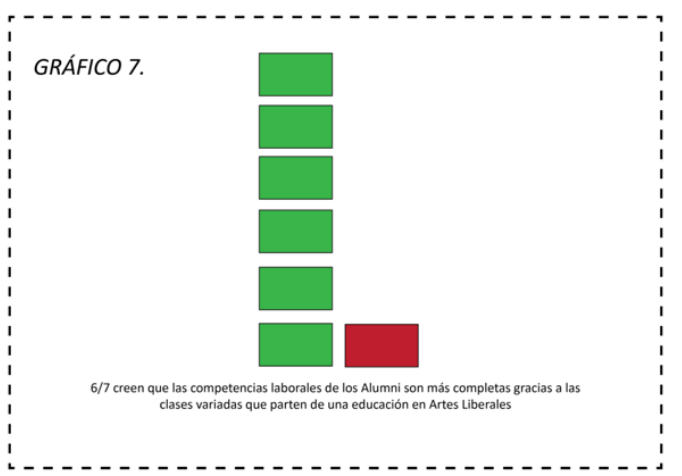

6 de los 7 entrevistados piensan que las competencias como Egresados de la Universidad San Francisco de Quito son más completas gracias a una educación basada en Artes Liberales. Los docentes nos dan comentarios como: "es un conocimiento más amplio, pero menos preciso" (Jaramillo, 2018), "los alumnos son más creativos y originales" (Rodríguez, 2018). Asimismo, algunos Egresados manifiestan que una de sus competencias gracias a las Artes Liberales es la fácil adaptabilidad a trabajos fuera de su campo regular. Este análisis se sustenta con lo dicho por Viviana y Rosa González que dice que competencias genéricas o transversales que se expresan en diferentes ámbitos profesionales para tener la capacidad de gestionar de forma autónoma y permanente el conocimiento (2008, p. 191), por lo tanto estos conocimientos fuera de la caja de la especialización del estudiante sí contribuyen con las competencias del mismo. 


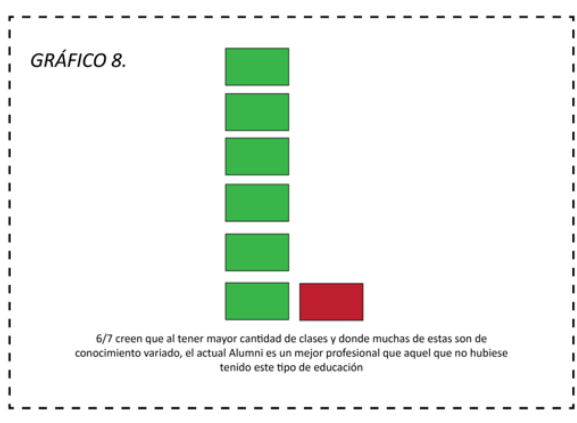

Por último, solamente un Egresado dice no creer ser mejor profesional a raíz de una educación en Artes Liberales, ya que piensa que adjetivos como mejor-peor no nacen a partir de un solo factor como el mencionado en esta investigación. Por otro lado, la mayoría de Egresados dice tener más aptitudes gracias a una universidad como la San Francisco. Ruth Rodríguez (2018), menciona que las Artes Liberales generan gusto por querer seguir aprendiendo, además los alumnos se vuelven críticos y, más importante incluso, se convierten en dueños de sus vidas ya que son libres de escoger y conocen sobre las opciones. Esto vuelve a ser corroborado por González y González al afirmar que la capacidad creativa, crítica y autocrítica y para tomar decisiones son parte de esta educación por competencias (2008, p. 201). Trujillo, asimismo asevera que se despliegan de mejor forma la autonomía y libertad del estudiante a partir de este mismo tipo de educación (2009, p. 16).

\section{c. Análisis de la trayectoria académica de los entrevistados}

- Como se detallo en las entrevistas, se muestra que en su mayoría 9 de cada 10, aprovecharon las materias de artes liberales que sus carreras ofrecían y siguieron, por lo que ha sido de mucha ayuda en su vida post universidad. El estudiar en una institución con la filosofía de Artes Liberales es de mucha ayuda, ya que abre el campo de visión. Sin embargo se pudo evidenciar que al inicio de su carrera creen muchas veces que es innecesario estudiar materias de colegio general (artes liberales) porque no tiene una validez académica o simplemente porque miran a este tipo de educación a manera de requisito y no como utilidad para su vida.

\section{d. Análisis de las condiciones actuales profesionales}

- Dentro del análisis sobre la trayectoria de los entrevistados, el 50\% dicen que las Artes Liberales ha sido de ayuda en su vida profesional, el 30\% de ellos dice que si ha tenido utilidad el tener el conocimiento de distintas áreas que te permiten ser, de alguna u otra forma, "más aceptados socialmente". Este término surge a partir de entrevistas, donde notamos que en la mayoría de los casos que respondieron que las Artes liberales si les ha ayudado en su vida profesional, y también lo hacen en el ámbito social. 


\section{e. Análisis de los aportes personales obtenidos por las materias multidisciplinarias}

- En la mayoría de los casos con más del $40 \%$ dicen que las materias multidisciplinarias no sirven dentro de su vida profesional. Sin embargo, existen varias opiniones que se pueden observar en las entrevistas, como el hecho en que brinda cultura, cultura en general, formas de comportarse y conocimientos adicionales que sirven para una conversación en un almuerzo con sus compañeros o el jefe, viajes o ejemplos parecidos que corroboran y justifican la utilidad de las materias de colegio general.

\section{CONCLUSIONES Y RECOMENDACIONES}

En este trabajo se analizaron los lineamientos institucionales relacionados con este estilo de enseñanza y se analizó las Artes Liberales y cómo influyen en el espíritu de la USFQ, como una Universidad que educa en libertad y promueve el emprendimiento y la educación holística para una amplia formación académica con bases de humanismo, para así enriquecer el perfil del egresado y prepararlo para un mejor desempeño laboral, ya que no están formándose para una sola área, sino que les permite a ellos mismos explorar según sus capacidades y competencias hasta dónde pueden llegar. Es ahí donde se comprueba que la educación basada en Artes Liberales promueve un mayor interés en desarrollar las aptitudes del estudiante, para que éste descubra por sí mismo hacia qué área le gustaría inclinarse en un futuro, emprender y ser líderes del cambio. Otro de nuestros objetivos analizados fue de comprobar con los Egresado si el modelo de Artes Liberales de la USFQ les ha ayudado en su vida profesional y personal y se pudo ver que en la muestra analizada la mayoría afirma que este modelo educativo les ha permitido desarrollarse no sólo en lo académico, sino también como seres humanos, pues afirman que las materias y seminarios socráticos impartidos en la universidad les ha ayudado a tener más opciones de desarrollo profesional, mejor interacción y mayor aceptación pues las materias optativas de este programa permiten desarrollar sus competencias, volviéndolos candidatos potenciales para un trabajo debido a sus conocimientos adicionales. Por otro lado, también en su vida personal se evidencia que las Artes Liberales han permitido que los egresado pueda desenvolverse haciendo lo que les apasiona, lo que a su vez permite que su desarrollo de creatividad que es demandada por su profesión de publicistas sea mayor, ya que la opción de realizar una sub especialización y las materias optativas permiten que el estudiante escoja en qué desarrollarse además de su carrera principal; por esta razón escogen materias y sub-especializaciones acordes a sus aptitudes, lo que fortalece no solo su formación académica sino su posibilidad de ampliar su desarrollo profesional y personal.

En conclusión, con la muestra escogida, la educación en Artes Liberales parece fomentar una formación en libertad, ya que permite que el estudiante se forme no solo en la carrera de su interés, sino 
que también pueda escoger el aprender lo que le gusta además de su vocación, lo que le prepara para un buen desempeño laboral basado en competencias, pues desarrolla nuevas aptitudes acorde a su interés de formación, lo que mejora su currículo y lo prepara para un amplio desenvolvimiento laboral. La formación en socráticos y humanidades abren su espectro de crecer personalmente, lo que los convierte en ciudadanos con un amplio criterio formado, capaces de dialogar, emprender y mejorar el área laboral de su interés y de vida personal. Como datos a destacar, es importante mencionar que los jóvenes aseguran no estar convencidos al principio de estudiar en Artes Liberales, pues muchos de ellos sintieron que se vieron forzados a tomar clases que no eran de su interés y lo veían como una obligación que no llamaba su atención, pues decían que al no pertenecer a su carrera y afines, estas clases eran descritas como una carga más para el estudio, pero que al final se dieron cuenta que de una u otra forma al estudiarlas les permitió ampliar su criterio y expandir sus horizontes de descubrimiento, y ahora las aplican en la vida diaria en ciertas ocasiones, todo gracias al programa de colegio general, en aspectos de vida personal como en el ámbito familiar y social, donde tienen argumentos que envuelven todos los diversos temas que conciernen a la sociedad actual. Por lo tanto, se ha evidenciado que existe ventajas considerables para considerar a la filosofía de Artes Liberales como una metodología que entrega a los alumnos herramientas y los convierte en mejores candidatos y más competentes para los trabajos a realizarse, se concluye también que la universidad debe trabajar más en hacer entender a sus alumnos actuales los beneficios de estudiar materias diferentes a su carrera o que les interesa pero no son necesariamente de la misma línea de sus carreras para beneficiarse de estos conocimientos y satisfacer sus curiosidades personales. 


\section{REFERENCIAS BIBLIOGRÁFICAS}

Anónimo. Trivium-Quadrivium. (28 /10/ 2009). ¿Qué es trívium y cuadrivium? Recuperado de http://trivium-quadrivium.blogspot.com/

Ardila, R (2003). Calidad de vida: una definición integradora en Revista

Latinoamericana de Psicología, vol. 35, núm. 2. (pp. 162-163). Recuperado el 16 de febrero de 2018 de http://www.redalyc.org/articulo.oa?id=80535203

Apuntes de filosofía. (20 de febrero 2009). La mayeútica de Sócrates. Recuperado de http://apuntesdefilosofa.blogspot.com/2009/02/la-mayeutica-de-socrates.html

Da Costa, R. (2006). Las definiciones de las siete artes liberales y mecánicas en la obra de Ramón Llull. Anales del Seminario de Historia de la Filosofía. (pp. 131-164). Brasil: Universidade Federal do Espírito Santo. Recuperado de http://www.ricardocosta.com/sites/default/files/pdfs/ashf0606110131a.pdf

De La Iglesia, J. (s. f.). Las Artes Liberales en la Biblioteca Real del Escorial, dos antecedentes iconográficos.

Recuperado

de

https://bibliotecavirtual.unl.edu.ar/ojs/index.php/CE/article/viewFile/1152/1794

González, V., González R. (2008). Competencias Genéricas Y Formación Profesional:

Un Análisis Desde La Docencia Universitaria. En Revista Iberoamericana De Educación. N. 47 (p. 191).

Mejía, A (1986). Educación Continua. (p.44). En Revista de Educación Médica y Salud

VOL $20 \quad \mathrm{~N}^{\circ}$ 1. Recuperado el 16 de febrero de 2018 de https://s3.amazonaws.com/academia.edu.documents/34829977/Educacion_continua.pdf?AWSAccessKe yId=AKIAIWOWYYGZ2Y53UL3A\&Expires=1518846863\&Signature=1 vtFXDUAb6Gg21iT7M4StQ oP3wE\%3D\&response-content-

disposition=inline\%3B\%20filename\%3DEDUCACION_CONTINUA.pdf

Rocerau, M., Vilanova, S. ( $1^{\text {o }}$ de noviembre 2008). El diálogo en el quehacer matemático: su valor como recurso. Revista Iberoamericana de Educación. Mar del Plata: Organización de Estados Iberoamericanos para la Educación, la Ciencia y la Cultura.

Romero, N (2005). ¿Y qué son las competencias? ¿Quién las construye? ¿Por qué

competencias? (p.12). Recuperado el 18 de febrero de 2017 de http://www.quadernsdigitals.net/datos_web/hemeroteca/r_24/nr_729/a_9909/9909.pdf

Cázares, L. (2016). Estrategias educativas para fomentar competencias. México: Trillas.

Tejada, R., Sánchez, P. (2012). La formación basada en competencias profesionales en los contextos universitarios. Manta: Mar Abierto.

Bain, Ken. (2007). Lo que hacen los mejores profesores universitarios. Valencia: Palacios.

Cázares, L., Cuevas, J. (2014). Planeación y evaluación basadas en competencias. México: Trillas.

Zabalza, M. (2013). Competencias docentes del profesor universitario. Bogotá: Narcea.

Sanz, M. (2013). Competencias cognitivas en educación superior. Bogotá: Narcea. 
Jaramillo, M. (2015). Las artes liberales, ¿forman mejores ciudadanos?: Un análisis experimental. Quito: USFQ. Recuperado de http://repositorio.usfq.edu.ec/handle/23000/4907

Trujillo, J. (2009). Formación humanística o formación por competencias: Dilemas de la educación en el contexto actual. Cali: Universidad del Valle. Recuperado de https://dialnet.unirioja.es/servlet/articulo?codigo=3686865

Corominas, E., Tesouro, M., Capell, D., et. al. (2006). Percepciones del profesorado ante la incorporación de las competencias genéricas en la formación universitaria. Revista de educación, 341, pp. 301-336. Girona: Universidad de Girona. Recuperado de https://dugidoc.udg.edu/handle/10256/9861?show=full

Aldana, A (2009). Formación humanística del estudiante universitario. En Studiocitas. Vol 4. (pp. 9-20). Recuperado de http://metadirectorio.org/bitstream/10983/559/1/Stud_4-3_A01_aldana-.pdf.

García, V., Del Barco, J., Círculo de educación Personalizada,. Et. al. (1996). La educación personalizada en la universidad. (p. 24). Recuperado de https://books.google.es/books?hl=es\&lr=\&id=6IHYh8VFrekC\&oi=fnd\&pg=PA131\&dq=las+artes+libe rales+en+la+educacion\&ots=KTMcAOiY_A\&sig=szmRUX-

etPKUzXcjHh5x1f_uncY\#v=onepage\&q=las\%20artes\%20liberales\%20en\%20la\%20educacion\&f=false

Schuldt, M. (s/f). Diez factores a considerar al elegir una Universidad. Recuperado de http://stufund.collegetoolkit.com/PDFGuides/RO/Spanish_InsidersGuideCollege.pdf

Fernández Rodríguez, E. (2009). El discurso de la formación basada en competencias profesionales. Un análisis crítico de la formación inicial de profesionales en la Educación Superior. Revista Electrónica Interuniversitaria de Formación del Profesorado, 12 (1), 151160. Recuperado de http://www.redalyc.org/pdf/2170/217015332011.pdf

Yoguez , A. (2009). ¿Cómo se evalúan las Universidades de Clase Mundial?. Revista de la educación superior, 38(150), 113-120. Recuperado en 18 de marzo de 2018, de http://www.scielo.org.mx/scielo.php?script=sci_arttext\&pid=S0185-

$27602009000200007 \& \operatorname{lng}=\mathrm{es} \& \ln \mathrm{ln}=\mathrm{es}$.

Gudiño, Sandra. (Abril, 2018). Entrevista.

Jaramillo. Néstor. (Abril, 2018). Entrevista.

Maridueña. María Gabriela. (Abril, 2018). Entrevista.

Páez, María Elena. (Abril, 2018). Entrevista.

Privitera, Mateo. (Abril, 2018). Entrevista.

Rodríguez, Ruth. (Abril, 2018). Entrevista.

Romero, Diana. . (Abril, 2018). Entrevista. 